\title{
Gene Duplication and Mutation in the Emergence of a Novel Aggressive Allele of the AVR-Pik Effector in the Rice Blast Fungus
}

\author{
Apinya Longya, ${ }^{1,2}$ Chaivarakun Chaipanya, ${ }^{1}$ Marina Franceschetti, ${ }^{2}$ Josephine H. R. Maidment, ${ }^{2}$ \\ Mark J. Banfield, ${ }^{2}$ and Chatchawan Jantasuriyarat ${ }^{1,3,+}$ \\ ${ }^{1}$ Department of Genetics, Faculty of Science, Kasetsart University, Bangkok, 10900, Thailand \\ ${ }^{2}$ Department of Biological Chemistry, John Innes Centre, Norwich Research Park, Norwich, NR4 7UH, U.K. \\ ${ }^{3}$ Center for Advanced Studies in Tropical Natural Resources, National Research University-Kasetsart University (CASTNAR, \\ NRU-KU), Kasetsart University
}

Accepted 2 January 2019.

\begin{abstract}
Higher yield potential and greater yield stability are common targets for crop breeding programs, including those in rice. Despite these efforts, biotic and abiotic stresses continue to impact rice production. Rice blast disease, caused by Magnaporthe oryzae, is the most devastating disease affecting rice worldwide. In the field, resistant varieties are unstable and can become susceptible to disease within a few years of release due to the adaptive potential of the blast fungus, specifically in the effector (avirulence $[A V R]$ ) gene pool. Here, we analyzed genetic variation of the effector gene $A V R-P i k$ in 58 rice blast isolates from Thailand and examined the interaction between $A V R-P i k$ and the cognate rice resistance gene $P i k$. Our results reveal that Thai rice blast isolates are very diverse. We observe four $A V R$-Pik variants in the population, including three previously identified variants, $A V R-P i k A, A V R-P i k D$, and $A V R-P i k E$, and one novel variant, which we named $A V R-P i k F$. Interestingly, 28 of the isolates contained two copies of $A V R-P i k$, always in the combination of $A V R-P i k D$ and $A V R-P i k F$. Blast isolates expressing only AVR-PikF show high virulence to rice cultivars encoding allelic $P i k$ resistance genes, and the AVR-PikF protein does not interact with the integrated
\end{abstract}

Sequence data from this article can be found in the GenBank databases under the following accession numbers: MH078516 (AVR-PikF), BioProject ID: PRJNA438312 (Magnaporthe oryzae isolate 10100), BioSample accession: SAMN08712647 (Magnaporthe oryzae isolate 10100), PYAN00000000 (Magnaporthe oryzae isolate 10100 whole-genome sequence), SRA accession: SRP152923 (Magnaporthe oryzae isolate 10100).

${ }^{\dagger}$ Corresponding author: C. Jantasuriyarat; fscicwj@ku.ac.th

Funding: This work was supported by Funding from The Thailand Research Fund (TRF) through The Royal Golden Jubilee Ph.D. Program (RGJ-Ph.D. Program) grant number PHD/0152/2556, Newton Fund Researcher Links: Travel Grant and Newton fund Ph.D. Placement, the Biotechnology and Biological Sciences (BBSRC, UK) grant numbers (grants $\mathrm{BB} / \mathrm{P} 012574$ and BB/M02198X), the ERC (proposal 743165), and The John Innes Foundation.

*The $\boldsymbol{e}$-Xtra logo stands for "electronic extra" and indicates that three supplementary figures are published online.

The author(s) declare no conflict of interest.

๑) 2019 The American Phytopathological Society heavy metal-associated domain of the Pik resistance protein in vitro, suggesting a mechanism for immune evasion.

Rice blast disease, caused by the ascomycete fungus Magnaporthe oryzae (syn. Pyricularia oryzae), is the most devastating disease of rice production worldwide (Couch and Kohn 2002). The fungus can affect all parts of the rice plant during all stages of growth (Zhang et al. 2014). The best strategy for control of blast disease is using genetically encoded resistant rice varieties. Plants, including rice, have developed basal defense responses that are triggered by detection of conserved microbe-associated molecular patterns, usually at the cell surface (Dodds and Rathjen 2010). Pathogens secrete effectors to the plant apoplast and inside of cells, many of which interfere with basal defense signaling and can re-establish disease (Hogenhout et al. 2009; Rafiqi et al. 2012). To respond to the presence of effectors delivered inside cells, plants have evolved intracellular immune receptors of the NLR (nucleotide-binding leucine-rich repeat) superfamily. Classicially, these receptors follow a 'gene-for-gene' relationship, in which a plant NLR recognizes a single pathogen effector. This recognition triggers the hypersensitive response and programmed cell death to block pathogen growth (Rafiqi et al. 2012). Coevolution between pathogens and hosts has driven diversification of effectors and NLRs. For example, an effector may be deleted from a pathogen genome or acquire amino acid polymorphisms that prevent recognition and this could be selected for in the population. In the latter case, the plant may acquire mutations in NLRs that re-establish recognition and disease resistance.

More than 100 rice blast disease resistance loci have been reported in the rice genome, and 30 of these have been cloned (Liu et al. 2014; Wang et al. 2017). Identification of the pathogen effectors recognized by these resistance proteins has lagged behind, and only 12 have been cloned to date, PWL1 (Kang et al. 1995), PWL2 (Sweigard et al. 1995), ACEl (Fudal et al. 2005), AVR-Pia (Yoshida et al. 2009), AVR-Pita (Orbach et al. 2000), AVR-Pik (Yoshida et al. 2009), AVR-Pii (Yoshida et al. 2009), AVR-Piz-t (Li et al. 2009), AVRl-CO39 (Ribot et al. 2013), AVR-Pi9 (Wu et al. 2015), AVR$P i b$ (Zhang et al. 2015), and AVR-Pi54 (Ray et al. 2016).

Thailand has a strong tradition of rice production. This crop is critical for the Thai economy and employs a significant portion of the labor force. Most Thai farmers elect to grow consumer-preferred rice varieties such as Khao Dawk Mali 105 (KDML105) and Kho Khor 6 (RD6) (Noenplab et al. 2006), but these are highly susceptible to rice blast disease. Rice blast 
epidemics have occurred in most provinces in the north and some in the northeast of Thailand (Disthaporn 1994; Khanthong et al. 2010). Jao Hom Nin (JHN) is a Thai nonsticky rice variety that has a long deep-purple grain (Waiyawuththanapoom et al. 2015). JHN demonstrated the highest broad-spectrum resistance against the rice blast pathogens in Thailand and the Philippines (Chaipanya et al. 2017; Sreewongchai et al. 2010). Two resistance genes in JHN were mapped. One, Pish, was mapped to chromosome 1 and shows a minor resistance phenotype, while the other, Pi7 (an allele in Pik locus), located on chromosome 11, has a major effect (Chaipanya et al. 2017).

Rice resistance genes at the $P i k$ locus encode multiple alleles (Pik*, Pikm, Pikp, Piks, Pikh, Pil, and Pi7) with differential resistance profiles to $M$. oryzae isolates (Chaipanya et al. 2017; Kanzaki et al. 2012). Pik comprises two open reading frames encoding NLR proteins Pik-1 and Pik-2, which are separated by approximately $2.5 \mathrm{~kb}$ of noncoding region and are oriented in opposite directions (Ashikawa et al. 2008). The Pik-1 gene shows a high number of DNA sequence polymorphisms, many of which are clustered within the integrated heavy metal-associated (HMA) domain that is responsible for the direct binding of the AVR-Pik effector (De la Concepcion et al. 2018; Langner et al. 2018; Maqbool et al. 2015). Furthermore, two amino acid residues at positions 229 and 252 were proposed as diagnostic markers for the classification of Pik alleles (Costanzo and Jia 2010) and both of these amino acids are located within the HMA domain. In contrast, the Pik-2 gene shows low levels of DNA polymorphism.

The $M$. oryzae AVR-Pik effector gene encodes a 113-amino acid protein with a 21-amino acid signal peptide (Yoshida et al. 2009). Five variants (alleles) of AVR-Pik (AVR-PikA, AVR-PikB, $A V R-P i k C, A V R-P i k D$, and $A V R-P i k E$ ) are different from each other by a total of five nucleotide substitutions (Fig. 1), all of which cause amino acid changes. The $A V R-P i k B$ variant is rare and is only found in a Japanese isolate (Yoshida et al. 2009).

Alleles of the rice NLR Pik show differential recognition specificities toward different $M$. oryzae AVR-Pik effector variants (De la Concepcion et al. 2018; Kanzaki et al. 2012). Rice expressing Pikp and Pi7 NLR alleles are only resistant to $M$. oryzae harboring AVR-PikD. Rice expressing Pikm is resistant to M. oryzae harboring AVR-PikA, AVR-PikD, or AVR-PikE (Chaipanya et al. 2017; Kanzaki et al. 2012), whereas rice expressing $P i k^{*}$ is only resistant to $M$. oryzae harboring AVR-PikD and AVR-PikE. The molecular basis for direct recognition of AVR-Pik variants by these NLR alleles is established (De la Concepcion et al. 2018; Maqbool et al. 2015,). The effector is bound by the Pik-HMA domain via three predominant interaction surfaces and amino acid changes in AVR-Pik at these interfaces (both natural variants and designed mutations) affects binding in vitro and celldeath phenotypes in the model system Nicotiana benthamiana.

In this study, the genetic variation of $A V R$-Pik from rice blast isolates in Thailand was investigated. Of the 58 Thailand isolates examined, 28 were found to encode two copies of the effector. We identify a novel $A V R$-Pik variant, which we name $A V R-P i k F$, and show that all rice cultivars tested are susceptible to $M$. oryzae strains expressing just this effector. Further, AVRPikF is not bound by the Pik-HMA domains in vitro and shows no cell-death phenotype in $N$. benthamiana, suggesting a mechanism for immune evasion by this variant. Together, this work further highlights how adaptation in pathogen effector genes can overcome disease resistance to blast in rice.

\section{RESULTS}

\section{Diverse and novel variants of the $A V R$-Pik effector} are found in the Thai $M$. oryzae population.

To identify genetic variation of $A V R$-Pik in Thai rice blast isolates, we amplified a 626-bp fragment encoding this gene alongside reference strains Guy11 and 70-15. We were able to amplify the AVR-Pik gene from 54 of 58 Thailand isolates (Table 1). Thai rice blast isolates were very diverse. AVR-Pik variants identified to date are different from each other by a total of five DNA substitutions, all of which cause amino acid changes. We found four AVR-Pik variants in the Thai isolates studied. These include three previously identified variants, AVR-PikA $(n=1), A V R-P i k D(n=22)$, and AVR-PikE $(n=1)$, and one novel variant, which was named $A V R-P i k F(n=2)$ (GenBank accession number MH078516). We also detected the variant $A V R-P i k C$, but only in the reference isolates Guy11 and $70-15(n=2)$. Interestingly, sequencing chromatograms from 28 of 56 positive isolates contained double peaks at four of five variable sites. To confirm this result, all 28 of these strains were re-isolated from single conidia and were cultured on rice flour agar (RFA) before repeating DNA extraction and AVR-Pik polymerase chain reaction (PCR) amplification and sequencing. The same results of double peaks in the sequencing data were obtained, indicating no cross-contamination of blast isolates. The PCR products encoding AVR-Pik from each of the 28 strains were then ligated with the pGEM-T Easy vector (Promega Madison) and were transformed into Escherichia coli DH5 $\alpha$ cells. Five white colonies (standard blue/white screening) per isolate were selected and cultured, and the plasmid DNA was extracted and sequenced. The results revealed that all 28 rice blast isolates contained two variants of the $A V R-P i k$ gene, specifically $A V R-P i k D$ and the new variant $A V R-P i k F$ (Table 1).

\section{Multiple copies of $A V R$-Pik are present \\ in some $M$. oryzae isolates.}

Next, we used quantitative real-time PCR to investigate copy number variation in a subset of Thai rice blast isolates. This analysis showed cycle threshold $(\mathrm{Ct})$ values for $A V R-P i k$ and the identified Magnaporthe oryzae gene (IDM) (a reference gene with one copy in the rice blast genome) to be near the 20th cycles with low standard deviation values, while the melting

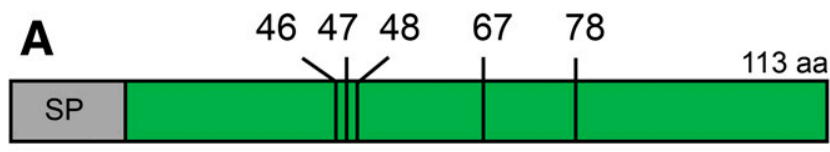

B

AVR-Pik polymorphic sites

\begin{tabular}{cccccc}
\hline \multirow{2}{*}{$\begin{array}{c}\text { AVR-Pik } \\
\text { alleles }\end{array}$} & \multicolumn{5}{c}{ Amino acid positions } \\
\cline { 2 - 6 } & 46 & 47 & 48 & 67 & 78 \\
\hline AVR-PikA & $\mathrm{N}$ & $\mathrm{A}$ & $\mathrm{D}$ & $\mathrm{A}$ & $\mathrm{M}$ \\
AVR-PikB & $\mathrm{N}$ & $\mathrm{A}$ & $\mathrm{D}$ & $\mathrm{A}$ & $\mathrm{I}$ \\
AVR-PikC & $\mathrm{N}$ & $\mathrm{P}$ & $\mathrm{G}$ & $\mathrm{D}$ & $\mathrm{M}$ \\
AVR-PikD & $\mathrm{H}$ & $\mathrm{P}$ & $\mathrm{G}$ & $\mathrm{A}$ & $\mathrm{M}$ \\
AVR-PikE & $\mathrm{H}$ & $\mathrm{P}$ & $\mathrm{G}$ & $\mathrm{A}$ & $\mathrm{M}$ \\
AVR-PikF & $\mathrm{N}$ & $\mathrm{A}$ & $\mathrm{D}$ & $\mathrm{A}$ & $\mathrm{K}$ \\
\hline
\end{tabular}

Fig. 1. Genetic diversity of Magnaporthe oryzae AVR-Pik. A, Schematic representation of the AVR-Pik effectors. SP indicates signal peptide. The positions of variable residues are as indicated. B, Amino acids of six AVR$P i k$ allelic products ( $A$ through $F$ ) for the five variable sites $(46,47,48,67$, and 78). 
curve results showed one peak for each gene. Following three biological replicates, the mean $A V R-P i k$ gene copy number of Guy11, TH196031, B1-2, 10100, 10301, BKK55001, RBR55001, and 10459 was $1.00,1.01,0.69,1.51,1.66,2.39$, 2.38 , and 2.11, respectively, relative to $I D M$ (Fig. 2). This result supports the sequencing results, suggesting that some rice blast isolates encode more than one copy of AVR-Pik.

Table 1. Rice blast isolates, location collected, year of collection, and its AVR-Pik allele

\begin{tabular}{|c|c|c|c|c|}
\hline No. & Isolate name & Origin & Year & $A V R-P i k$ allele $(\mathbf{s})^{a}$ \\
\hline 1 & 10100 & Srakaew & 2006 & $\mathrm{D}$ and $\mathrm{F}$ \\
\hline 2 & 10301 & Sisaket & 2006 & $\mathrm{D}$ and $\mathrm{F}$ \\
\hline 3 & 10302 & Sisaket & 2006 & $\mathrm{D}$ and $\mathrm{F}$ \\
\hline 4 & 10459 & Lampang & 2006 & $\mathrm{D}$ and $\mathrm{F}$ \\
\hline 5 & 10551 & Nakhon Ratchasima & 2006 & $\mathrm{D}$ \\
\hline 6 & 10552 & Nakhon Ratchasima & 2006 & $\mathrm{D}$ \\
\hline 7 & 10576 & Kalasin & 2006 & $\mathrm{D}$ and $\mathrm{F}$ \\
\hline 8 & 10577 & Nakhon Ratchasima & 2006 & $\mathrm{D}$ and $\mathrm{F}$ \\
\hline 9 & 10578 & Nakhon Ratchasima & 2006 & $\mathrm{D}$ and $\mathrm{F}$ \\
\hline 10 & 10581 & Nakhon Ratchasima & 2006 & $\mathrm{D}$ and $\mathrm{F}$ \\
\hline 11 & 10652 & Maha Sarakham & 2006 & $\mathrm{D}$ \\
\hline 12 & 10681 & Roi Et & 2006 & $\mathrm{D}$ and $\mathrm{F}$ \\
\hline 13 & 10694 & Nongkhai & 2006 & $\mathrm{D}$ \\
\hline 14 & 10732 & Kamphaengphet & 2006 & $\mathrm{D}$ and $\mathrm{F}$ \\
\hline 15 & 10760 & Kamphaengphet & 2006 & $\mathrm{D}$ and $\mathrm{F}$ \\
\hline 16 & 10812 & Chiangrai & 2006 & $\mathrm{D}$ \\
\hline 17 & 10837 & Surin & 2006 & $\mathrm{D}$ and $\mathrm{F}$ \\
\hline 18 & 10873 & Maehongson & 2006 & $\mathrm{D}$ and $\mathrm{F}$ \\
\hline 19 & 10926 & Phayao & 2006 & $\mathrm{D}$ and $\mathrm{F}$ \\
\hline 20 & 10927 & Phayao & 2006 & $\mathrm{D}$ and $\mathrm{F}$ \\
\hline 21 & 10941 & Lampang & 2006 & $\mathrm{D}$ and $\mathrm{F}$ \\
\hline 22 & 10971 & Nan & 2006 & $\mathrm{D}$ and $\mathrm{F}$ \\
\hline 23 & 10985 & Sisaket & 2006 & $\mathrm{D}$ \\
\hline 24 & 10993 & Buriram & 2006 & $\mathrm{D}$ and $\mathrm{F}$ \\
\hline 25 & 11100 & Udonthani & 2006 & $\mathrm{D}$ and $\mathrm{F}$ \\
\hline 26 & 11108 & Ubon Ratchathani & 2006 & $\mathrm{D}$ and $\mathrm{F}$ \\
\hline 27 & 11109 & Ubon Ratchathani & 2006 & $\mathrm{D}$ and $\mathrm{F}$ \\
\hline 28 & BAG1.2 & Phitsanulok & 2006 & $\mathrm{D}$ \\
\hline 29 & BAG4.6 & Phitsanulok & 2006 & $\mathrm{D}$ \\
\hline 30 & 40.3 & - & - & A \\
\hline 31 & SRN54001 & Surin & 2011 & $\mathrm{D}$ \\
\hline 32 & SRN54002 & Surin & 2011 & $\mathrm{D}$ \\
\hline 33 & SRN54005 & Surin & 2011 & $\mathrm{D}$ \\
\hline 34 & SRN54006 & Surin & 2011 & $\mathrm{D}$ \\
\hline 35 & SRN54007 & Surin & 2011 & $\mathrm{D}$ \\
\hline 36 & SRN54009 & Surin & 2011 & $\mathrm{D}$ \\
\hline 37 & CCO56001 & Chachoengsao & 2013 & $\mathrm{D}$ and $\mathrm{F}$ \\
\hline 38 & CCO56002 & Chachoengsao & 2013 & $\mathrm{D}$ and $\mathrm{F}$ \\
\hline 39 & CCO56003 & Chachoengsao & 2013 & $\mathrm{D}$ \\
\hline 40 & CCO56004 & Chachoengsao & 2013 & $\mathrm{D}$ \\
\hline 41 & CPM55001 & Chaiyaphum & 2012 & $\mathrm{D}$ \\
\hline 42 & CPM55002 & Chaiyaphum & 2012 & $\mathrm{D}$ \\
\hline 43 & CPM55003 & Chaiyaphum & 2012 & $\mathrm{D}$ and $\mathrm{F}$ \\
\hline 44 & NYK55001 & Nakhon Nayok & 2011 & $\mathrm{D}$ \\
\hline 45 & NYK55003 & Nakhon Nayok & 2011 & $\mathrm{D}$ \\
\hline 46 & BKK55001 & Bangkok & 2011 & $\mathrm{D}$ and $\mathrm{F}$ \\
\hline 47 & BKK55002 & Bangkok & 2011 & $\mathrm{D}$ and $\mathrm{F}$ \\
\hline 48 & BKK55003 & Bangkok & 2011 & $\mathrm{D}$ and $\mathrm{F}$ \\
\hline 49 & RBR55001 & Ratchaburi & 2011 & $\mathrm{D}$ and $\mathrm{F}$ \\
\hline 50 & RBR55002 & Ratchaburi & 2011 & $\mathrm{D}$ \\
\hline 51 & RBR55003 & Ratchaburi & 2011 & $\mathrm{D}$ \\
\hline 52 & B1-2 & Ubon Ratchathani & 2001 & $\mathrm{E}$ \\
\hline 53 & TH196031 & Ubon Ratchathani & 2001 & $\mathrm{~F}$ \\
\hline 54 & TH196036 & Ubon Ratchathani & 2001 & $\mathrm{~F}$ \\
\hline 55 & TRG1 & Nongkhai & 2013 & None \\
\hline 56 & TRG2 & Nongkhai & 2013 & None \\
\hline 57 & TRG3 & Nongkhai & 2013 & None \\
\hline 58 & TRG4 & Nongkhai & 2013 & None \\
\hline 59 & $70-15$ & Laboratory strain & 1988 & $\mathrm{C}$ \\
\hline 60 & Guy11 & French Guyana & 1988 & $\mathrm{C}$ \\
\hline
\end{tabular}

${ }^{a}$ AVR-Pik allele analysis by sequencing.
Southern blot analysis was carried out to validate the $A V R$ $P i k$ copy number in the rice blast genome. Genomic DNA of rice blast isolates was digested with $B a m \mathrm{HI}$, five rice blast isolates that contained one copy of $A V R$-Pik (variants $A V R$ PikA, AVR-PikC, AVR-PikD, AVR-PikE, and AVR-PikF) showed one hybridization signal at $4 \mathrm{~kb}$ in size with the $A V R$-Pik probe (Fig. 3A). When using four rice blast isolates with a single copy of $A V R-P i k D$, the result showed two different hybridization signal sizes, either 4 or $6.2 \mathrm{~kb}$ (Fig. 3B). Three of the five rice blast isolates containing two copies of AVR-Pik, namely, 10301, 11108 , and 10760, showed two hybridization signals at 4 and $6.2 \mathrm{~kb}$ in size. The other two isolates showed only one signal at $4 \mathrm{~kb}$ (Fig. 3A). When using PstI restriction enzyme, the result was consistent with that observed using BamHI. Six rice blast isolates containing one copy of $A V R$-Pik showed one hybridization signal at 4 or $5.2 \mathrm{~kb}$. Two isolates that both contained $A V R-P i k D$ showed two different hybridization signal sizes, one $4 \mathrm{~kb}$ and the other $5.2 \mathrm{~kb}$. Two of four rice blast isolates (10100 and 10576) containing two copies of AVR-Pik showed two hybridization signals and the remaining two isolates showed a more intense signal at $5.2 \mathrm{~kb}$. The rice blast isolate TRG1, which lacks AVR-Pik and therefore gives no PCR amplification product with $A V R$-Pik-specific primers showed no hybridization signal (Fig. 3C).

\section{Whole-genome sequencing confirms the presence of two $A V R$-Pik variants in rice blast isolate 10100 .}

To confirm the results of the copy number analysis above, we re-sequenced the whole genome of rice blast isolate 10100, which our previous work suggested contained two copies of the AVR-Pik gene. This sequencing generated 3,159 scaffolds, approximately $39.55 \mathrm{Mb}$ in total size, with N50 scaffold length = 108,598 and L50 scaffold count $=92$. Scaffold \% A, C, G, T, and

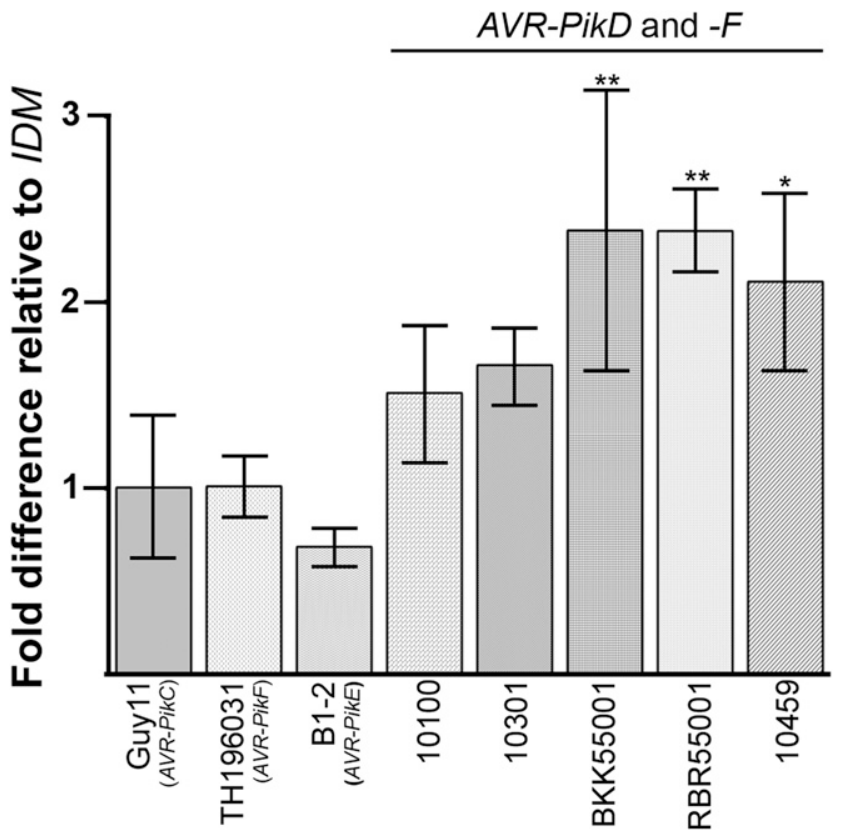

Fig. 2. Real-time polymerase chain reaction calculates the copy number by comparative cycle threshold $(\mathrm{Ct})$ method with the IDM gene. Relative quantification calculates the copy number by comparative $\mathrm{Ct}$ method (also referred to as the $2^{\Delta \mathrm{Ct}}$ method) with IDM gene. Guy11, TH196031, and B12 represent $A V R$-Pik alleles $\mathrm{C}, \mathrm{F}$, and $\mathrm{E}$, respectively, and isolates 10100 , 10301, BKK55001, RBR55001, and 10459 contained two AVR-Pik alleles from sequencing. The result shows that the AVR-Pik gene has more than one copy in some isolates. The levels of statistical significance were represented as with one asterisk $(*)$ for $P \leq 0.05$, two $(* *)$ for $P \leq 0.01$. 
$\mathrm{N}$ are 24.26, 25.37, 25.41, 24.27, and 0.68, respectively (GenBank accession number PYAN00000000, SRA accession number SRP152923). Two contigs were shown to contain a copy of the AVRPik gene. Contig1790, a minus strand of 705 bp in length, had a sequence $100 \%$ identical to $A V R-P i k D$, and Contig1787, a plus strand of 709 bp in length, had a sequence $100 \%$ identical to AVRPikF (Supplementary Fig. S2). The two contigs share $98.59 \%$ similarity, with four indels and two polymorphic sites upstream of the AVR-Pik gene and four polymorphic sites within the gene that differentiate the $A V R$-Pik variants.

\section{Multiple $A V R$-Pik variants are expressed during $M$. oryzae infection of rice.}

To test whether both $A V R$-Pik variants are expressed in isolates encoding $A V R-P i k D$ and $A V R-P i k F$ during infection, we prepared complementary DNA (cDNA) from total RNA of rice leaf tissue infected with strain 10100. We then used $A V R$ $P i k \_c d s$ primers to amplify the effector gene, with an expected size of $342 \mathrm{bp}$. The resulting AVR-Pik cds amplicon was

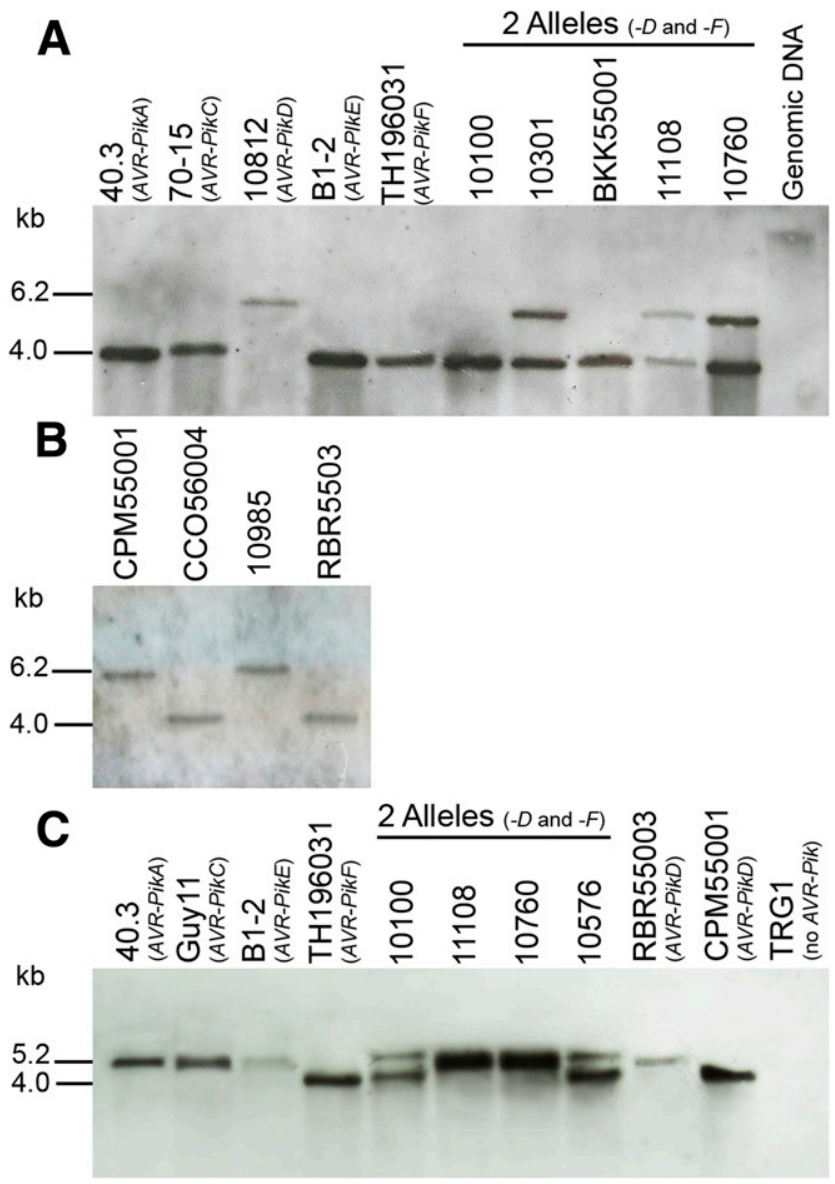

Fig. 3. Genomic Southern hybridization analysis of the AVR-Pik. A, Genomic DNA was digested by BamHI, and was hybridized with the AVR-Pik fragment; molecular sizes in kilobases are shown on the left. Lanes 1 to 5 represent rice blast isolates with different $A V R$ - $P i k$ alleles, $A V R-P i k A, A V R$ $P i k C, A V R-P i k D, A V R-P i k E$, and AVR-PikF, respectively. Lanes 6 to 10 show rice blast isolates with two copies of $A V R-P i k$, and lane 11 was undigested genomic DNA as a control. B, The four random AVR-PikD isolates that showed both different $A V R$-Pik signal sizes. C, Genomic DNA was digested by $P s t \mathrm{I}$ and was hybridized with the AVR-Pik fragment. Lanes 1 to 4 represent rice blast isolates with different $A V R$-Pik alleles, (AVRPikA, AVR-PikC, AVR-PikE, and AVR-PikF, respectively). Lanes 5 to 8 show rice blast isolates with two copies of $A V R-P i k$. Lanes 9 and 10 show rice blast isolates with $A V R-P i k D$ and lane 11 was rice blast isolate TRG1, as negative control. Molecular sizes in kilobases are shown on the left. purified and sequenced. Chromatogram of PCR products showed a double peak at $A V R$ - $P i k$ variable sites (Supplementary Fig. S3). This result indicated that both $A V R-P i k D$ and $A V R-$ $P i k F$ are expressed during rice infection.

\section{Pik NLR alleles in rice do not respond} to $M$. oryzae strains expressing $A V R-P i k F$.

To investigate the pathogenicity of rice blast isolates expressing different $A V R$-Pik variants on Thai rice cultivars JHN and KDML105, we spray-inoculated 21-day-old rice seedlings. We find that KDML105 was susceptible to all rice blast isolates (Fig. 4). JHN was susceptible to rice blast isolates encoding $A V R$ - $P i k$ variants AVR-PikA, AVR-PikC, AVR-PikE, and AVR$P i k F$ but showed resistance to an isolate with $A V R-P i k D$ and an isolate encoding two copies of the effector, $A V R-P i k D$ and $A V R$ $P i k F$. The result suggested that $A V R-P i k D$ was specifically recognized by $P i 7$ from JHN (Fig. 4).

As $P i 7$ is an ortholog of the rice NLR Pik, we screened a panel of eight $P i k$ international rice blast monogenic line (IRBL) rice near-isogenic lines (NILs) from the International Rice Research Institute (IRRI). These NILs harbor Pik alleles Pik*, Pikp, Pikm, Pikh, Piks, Pil, and Pi7 (and also includes the negative control $P i k^{-}$). Each of these NILs were sprayinoculated with three rice blast isolates encoding either $A V R$ $P i k D, A V R-P i k F$, or both AVR-PikD and AVR-PikF. The background cultivar of the NILs, Lijiang Xintuan Heigu (LTH),

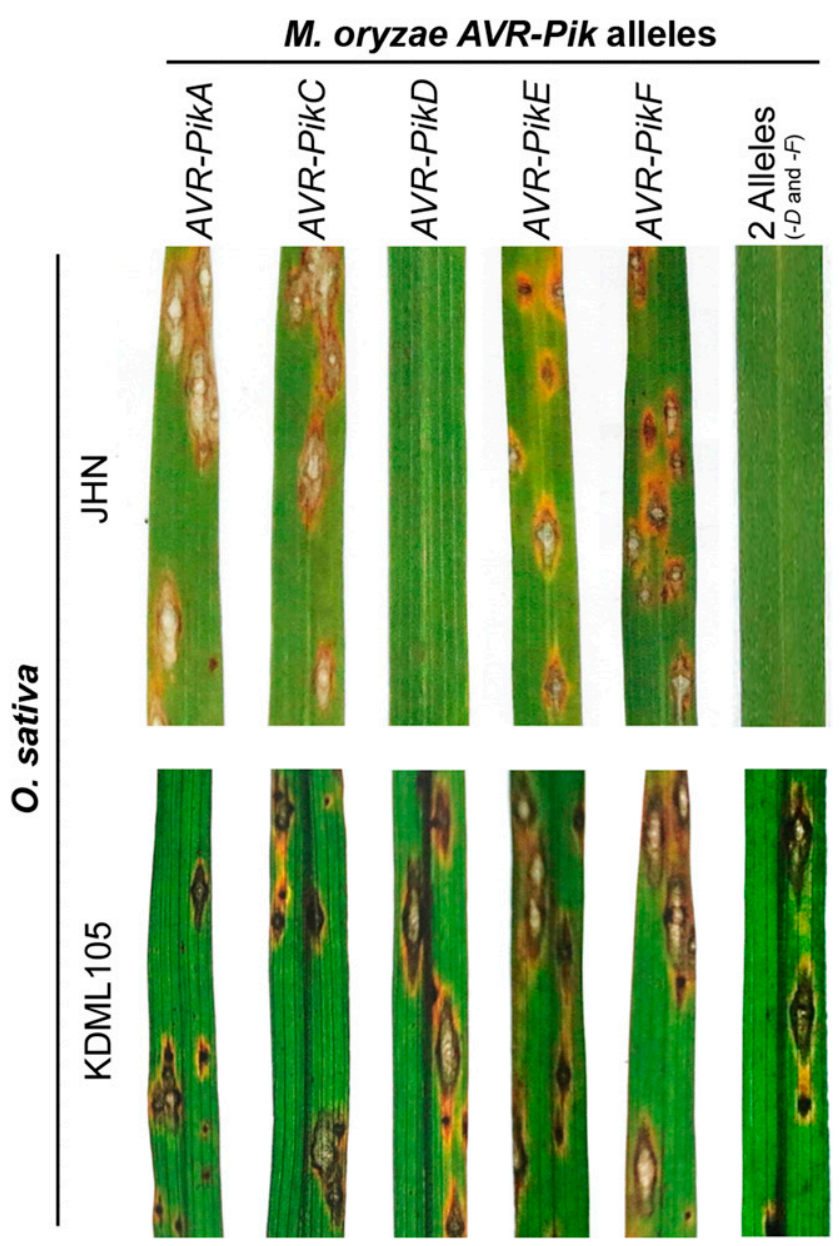

Fig. 4. Pathogenicity assay showing recognition specificity of Magnaporthe oryzae AVR-PikD allele by Pi7 resistance gene in Jao Hom Nin (JHN). Khaw Dawk Mali 105 (KDML105) was used as susceptible control, symptoms on rice cultivars 7 days after inoculation with each rice blast AVR-Pik isolate. 
without a $P i k$ gene $\left(P i k^{-}\right)$and rice cultivar IRBLKS-F5 containing $P i k$ genes were both susceptible to all three blast isolates. The Pik NILs, Pik*, Pikp, Pikm, Pikh, Pil, and Pi7, were resistant to $M$. oryzae harboring $A V R-P i k D$ and both $A V R-P i k D$ and $A V R-P i k F$. Interestingly, all the rice cultivars tested were susceptible to $M$. oryzae harboring $A V R-P i k F$ (Fig. 5). This result identifies $A V R-P i k F$ is a previously undescribed aggressive variant that is not recognized by any tested $P i k$ resistance allele.

\section{AVR-PikF evades detection by Pik NLRs through disruption of protein interactions.}

We hypothesized that AVR-PikF evades recognition by the Pik NLRs in rice because the mutation Met78Lys disrupts binding to the integrated HMA domains. This mutation is unique to AVR-PikF and distinguishes it from the effector variant AVR-PikA (Fig. 1). AVR-PikA, AVR-PikD, and AVR-PikE bind to the Pikm-HMA in vitro, forming stable complexes detectable by analytical gel filtration, but AVR-PikC does not (De la Concepcion et al. 2018). M. oryzae strains expressing AVRPikC are not recognized by the Pik NLRs Pikm or Pikp. We tested whether AVR-PikF could bind to either Pikm-HMA or Pikp-HMA in vitro using analytical gel filtration; the interaction of Pikm-HMA and Pikp-HMA with AVR-PikD was used as a positive control. We found no evidence of AVR-PikF binding to either the Pikm-HMA or Pikp-HMA using this assay. In contrast to AVR-PikD, no shift in retention volume was observed for AVR-PikF when the proteins were mixed, as compared with the protein alone (Fig. 6A to D).

To further support the idea that the phenotype of susceptibility in rice to $M$. oryzae strains expressing AVR-PikF is due

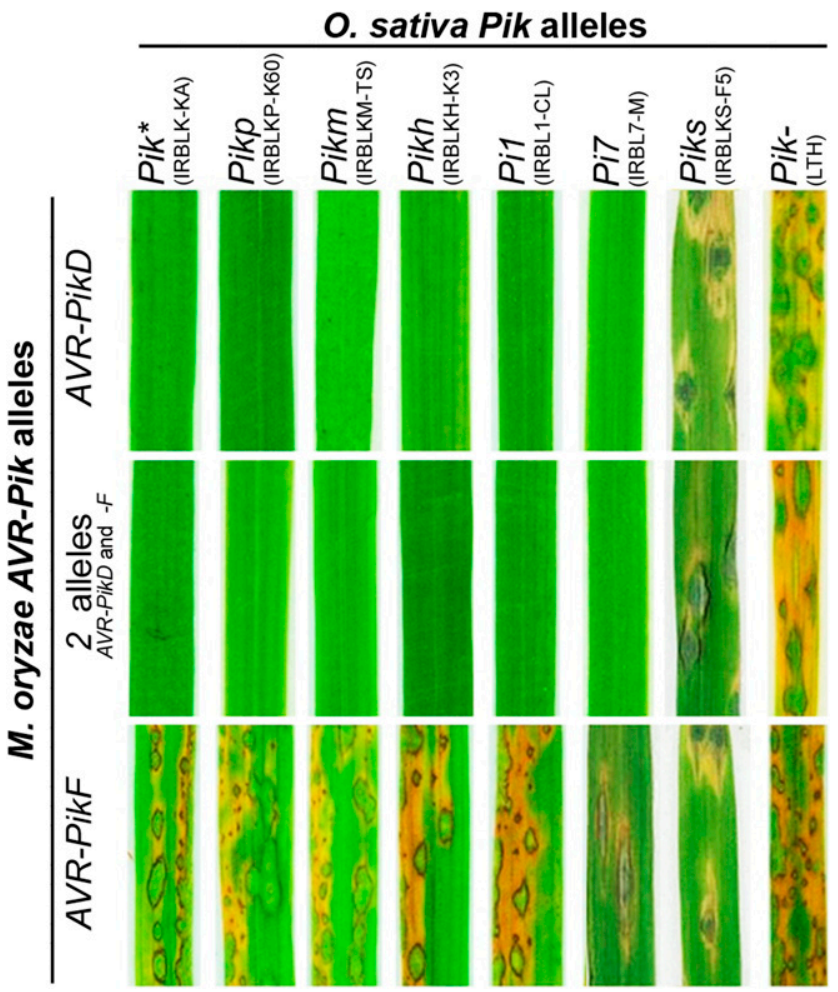

Fig. 5. Pathogenicity assay showing recognition specificity of Magnaporthe oryzae AVR-Pik alleles AVR-PikD, AVR-PikF to rice cultivars containing different Pik alleles. All M. oryzae isolates were spray inoculated into Pik near-isogenic lines IRBLK-KA ( $\left.P i k^{*}\right)$, IRBLKP-K60 (Pikp), IRBLKM-TS (Pikm), IRBLKH-K3 (Pikh), IRBL1-CL (Pi1), IRBL7-M (Pi7), IRBLKSF5 (Piks), and Lijiang Xintuan Heigu (LTH) $\left(P i k^{-}\right)$. specifically to the lack of recognition of the effector by Pik NLRs, we performed a cell-death assay in $N$. benthamiana. This assay has proven very robust in correlating Pik-dependent cell death in $N$. benthamiana with immunity in rice. We find that, although the positive controls of either Pikp or Pikm with AVR-PikD give a robust cell-death phenotype, neither Pikp nor Pikm respond to AVR-PikF (Fig. 7).

\section{DISCUSSION}

The AVR-Pik effector escapes $P i k$-mediated plant immunity by gene substitution and gene duplication. A single amino acid change has given rise to a novel $A V R$-Pik allele, $A V R-P i k F$, which shows high virulence to all rice allelic $P i k$ resistance genes through perturbation of the effector-Pik-HMA domain binding interface. Duplication of the $A V R-P i k$ gene in rice blast isolates has resulted in the presence of two different alleles in the same $M$. oryzae isolate, one avirulent allele, $A V R-P i k D$, and one virulent allele, $A V R-P i k F$. As $A V R-P i k F$ may represent an emerging $A V R$-Pik allele in pathogen populations, it is important to develop Pik variants that can detect $A V R-P i k F$ and mount an immune response.

\section{$A V R$-Pik variation in rice blast isolates.}

New virulent isolates of the rice blast pathogen can emerge by genetic modification of effector $(A V R)$ genes by different mechanisms. Nonsynonymous point mutations in AVR-Pita, AVR-Pia, AVR-Pii, and AVR-Pik (Dai et al. 2010; Takahashi et al. 2010; Yoshida et al. 2009), transposon insertions in ACE1, AVR-Piz-t, AVR-Pib, and AVR-Pital (Fudal et al. 2009; Li et al. 2009; Zhang et al. 2015; Zhou et al. 2007), and sexual mating and parasexual recombination (Tsujimoto Noguchi 2011) have all been shown to lead to virulent alleles. Previous reports showed that $M$. oryzae effector genes are highly diverse and are capable of rapid change in natural populations (Jia et al. 2000; Sirisathaworn et al. 2017). Yoshida et al. (2009) revealed that the DNA sequence of $A V R$-Pik is highly variable, with a nucleotide diversity of $7.1 \times 10^{3}$, two orders higher than the mean value for the entire genome $\left(8.2 \times 10^{5}\right)$. Consistent with this, we found that the AVR-Pik gene in Thai rice blast isolates shows a high level of genetic diversity, and a novel aggressive allele, $A V R-P i k F$, was identified. We speculate that selection pressure from the use of rice varieties containing the $P i k$ resistance gene in Thailand may have driven the emergence of this allele.

Pathogen evolution by gene duplication and translocation.

Using resistant cultivars in breeding for blast disease resistance in rice is effective, saving labor and costs, with the ability to reduce chemical inputs in agriculture and, ultimately, increase yield. However, newly developed resistant cultivars frequently lose their ability to prevent blast disease within a few years through rapid pathogen adaptation (Kiyosawa 1982). The mechanism of adaptation is mainly by amino acid substitution and gene duplication. Two mechanisms for gene duplication in fungi are sexual mating and parasexual recombination (Tsujimoto Noguchi 2011), but sexual reproduction in the rice blast fungus has not been observed directly in the field, so parasexual recombination is most likely the major determinant cause of gene duplication in M. oryzae (Saleh et al. 2014). Parasexual DNA exchanges occur at a detectable frequency in the field and may provide opportunities for different isolates to exchange supernumerary chromosomes or DNA fragments carrying effector genes (Chuma et al. 2011; Zeigler et al. 1997). This causes variation in the pathogenicity of the rice blast fungus, leading to breakdown of genetically encoded resistance (Tsujimoto Noguchi 2011; Yamasaki and Niizeki 1965). AVRPita is located on supernumerary chromosomes in some 
M. oryzae isolates, and this is potentially involved in AVR gene dynamics through their loss, horizontal transfer, and structural change, including gene duplications (Chuma et al. 2011). We found evidence of gene duplication of $A V R-P i k$ in Thai isolates of the rice blast fungus. Of these isolates, 28 of $58(48.28 \%)$ contained two copies of AVR-Pik, AVR-PikD and AVR-PikF, with both alleles expressed during rice infection. Full genome sequencing of isolate 10100 revealed two AVR-Pik genes located on two different contigs. The presence of rice blast isolates containing two AVR-Pik alleles was described previously by Yoshida et al. (2009). They found six of 16 rice blast isolates in Japan contained two copies of the AVR-Pik gene (AVR-PikA and $A V R-P i k D)$. Kusaba et al. (2014) also reported that rice blast isolate $84 \mathrm{R}-62 \mathrm{~B}$ contained two copies (AVR-PikA and $A V R-P i k D)$ and has undergone translocation via supernumerary chromosomes. These findings support the hypothesis that the AVR-Pik gene undergoes a high level of genetic recombination (Kusaba et al. 2014; Luo et al. 2007). The pathogenicity assay of rice blast isolates with two AVR-Pik alleles was the same as those isolates with one $A V R-P i k D$ allele, which were avirulent. This result indicates that the Pik resistance proteins can recognize the AVR-PikD effector in the presence of AVR-PikF and this leads to a defense response. In contrast, rice blast isolates with only $A V R-P i k F$ are virulent to all Pik NILs. This finding supports gene duplication as a mechanism for the fungal adaptation and evolution. The 28 rice blast isolates with two copies of the AVR-Pik gene from our study, six rice blast isolates from Yoshida et al. (2009), and the 84R-62B isolate from Kusaba et al. (2014) each contained $A V R-P i k D$ and a virulent $A V R-P i k$ allele. The avirulent isolates, containing only $A V R$ $P i k D$, show reduced survival in the rice field because $A V R-P i k D$ can be recognized by many $P i k$ alleles. The emergence of rice blast isolates with two copies of the AVR-Pik gene, one avirulent allele and one virulent allele, may lead to aggressive rice blast isolates by subsequent loss of $A V R-P i k D$. The importance and prevalence of this mechanism of pathogen adaptation requires further study.

\section{Direct AVR-Pik-Pik-HMA interaction underpins immunity.}

Amino acid polymorphisms in AVR-Pik variants correlate with evasion of immunity by disrupting direct binding of the effector to the integrated HMA domain of Pik NLR alleles (De la Concepcion et al. 2018). The protein-protein interfaces formed between effector variants and Pik-HMA domains are well-established (De la Concepcion et al. 2018; Maqbool et al. 2015). Compared with AVR-PikD, AVR-PikF has four amino acid polymorphisms (Fig. 1). Three of these are shared with the effector variant AVR-PikA, at amino acids 46, 47, and 48, with the fourth being the defining mutation in AVR-PikF, a Met to Lys substitution at amino acid 78. AVR-PikD and AVR-PikA both bind to the HMA domain from the Pikm allele (PikmHMA), and this NLR responds to these effectors in both $N$. benthamiana (cell death) and rice (immunity). AVR-PikF escapes detection in plants by all tested Pik NLR alleles and does not interact with the Pikm-HMA or Pikp-HMA domains in vitro. The amino acid at position 78 is part of an extensive interface observed in the structures of AVR-Pik effectors in complex with Pik-HMA domains (termed 'interface 3' by De la Concepcion et al. 12018]) (Fig. 8). We speculate that as the Met78Lys mutation introduces both a larger side chain and a positive charge at this position (Fig. 8), this will disrupt contacts across this interface. This disruption results in an incompatible interaction between the effector and Pik-HMA domain that translates into evasion of immunity in rice.

\section{Long term use of the Pik locus in Thai rice varieties.}

The most effective tool to control rice blast in the field is to breed new disease-resistant rice varieties. JHN is a Thai rice variety showing broad-spectrum resistance against rice blast in Thailand (Sreewongchai et al. 2010). Two rice blast resistance genes were cloned on chromosomes 1 and 11 of JHN (Chaipanya et al. 2017). Pi7-J is located at the Pik locus on chromosome 11 and Pish is located on chromosome 1 (Chaipanya et al. 2017). JHN has been widely used as an elite resistant donor in conventional and molecular breeding programs against rice blast disease in Thailand (Noenplab et al. 2015). Examples of varieties from these breeding programs are RD6 (Wongsaprom et al. 2010), KDML105 (Nalampangnoenplab 2011), IR7795524-75-284 (Kotchasatit 2013), Ban Tang (Kaewcheenchai et al. 2014), Jao Hawm Phitsanulok51 (Noenplab et al. 2015), and San Par Tong1 (Yajai and Ketsuwan 2015). From pathogenicity assays, we found that $\mathrm{JHN}$ is resistant to $M$. oryzae isolates expressing $A V R-P i k D$, either alone or in isolates expressing
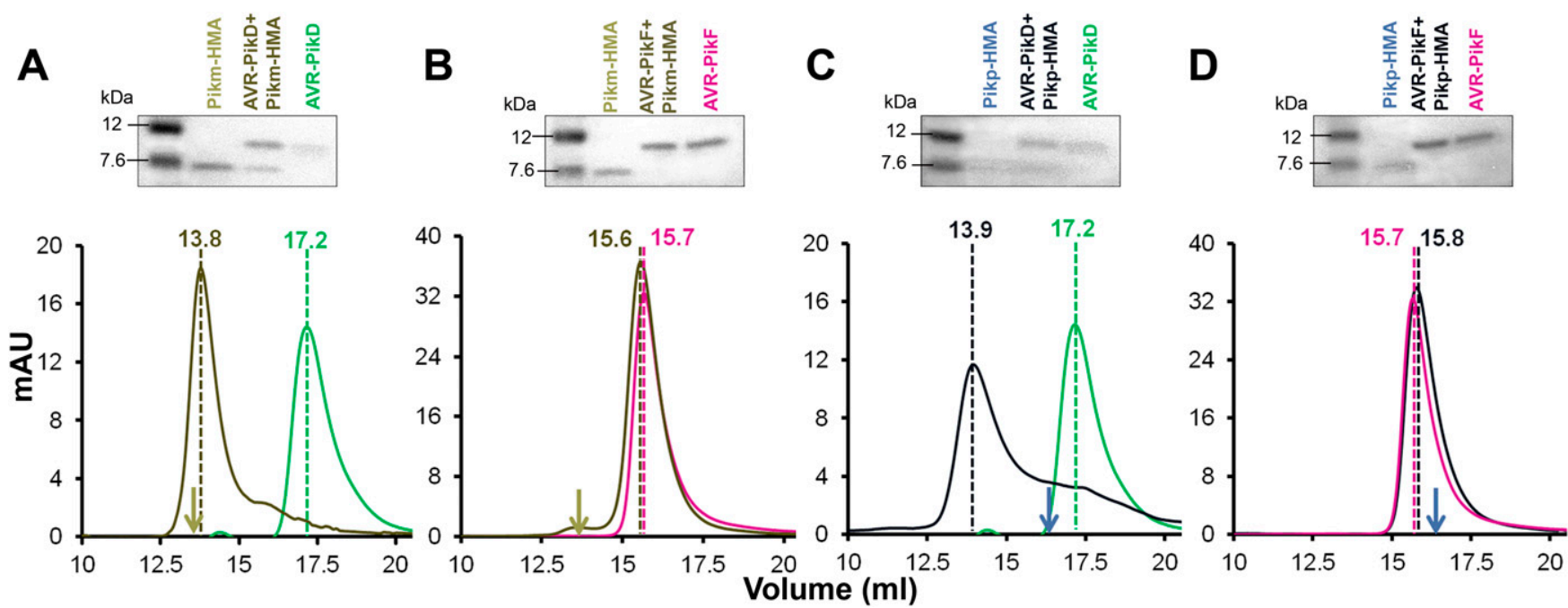

Fig. 6. Analytical gel filtration traces depicting the retention volume of AVR-PikD, AVR-PikF, Pikm-HMA, and Pikp-HMA individually and when effector and the heavy metal-associated (HMA) domain are mixed confirm that A, Pikm-HMA and C, Pikp-HMA form complexes with AVR-PikD but B, Pikm-HMA and D, Pikp-HMA do not form complexes with AVR-PikF. The arrows indicate Pik-HMA elution volume (does not absorb light at $280 \mathrm{~nm}$ ). Sodium dodecyl sulfate polyacrylamide electrophoresis gels of the relevant fractions from the elution traces of the effectors. Pik-HMA is also shown. 
both $A V R-P i k D$ and $A V R-P i k F$ (Fig. 4) but not other AVR-Pik effector variants. This is an identical profile to the previously described Pikp. Multiple sequence alignment of Pik-HMA domains revealed that the $P i 7-H M A$ domain was identical at the amino acid level to Pikp (99.57\% identical at the DNA level, with just a single synonymous base polymorphism). This suggests that using rice variety $\mathrm{JHN}$ as an elite resistant donor in

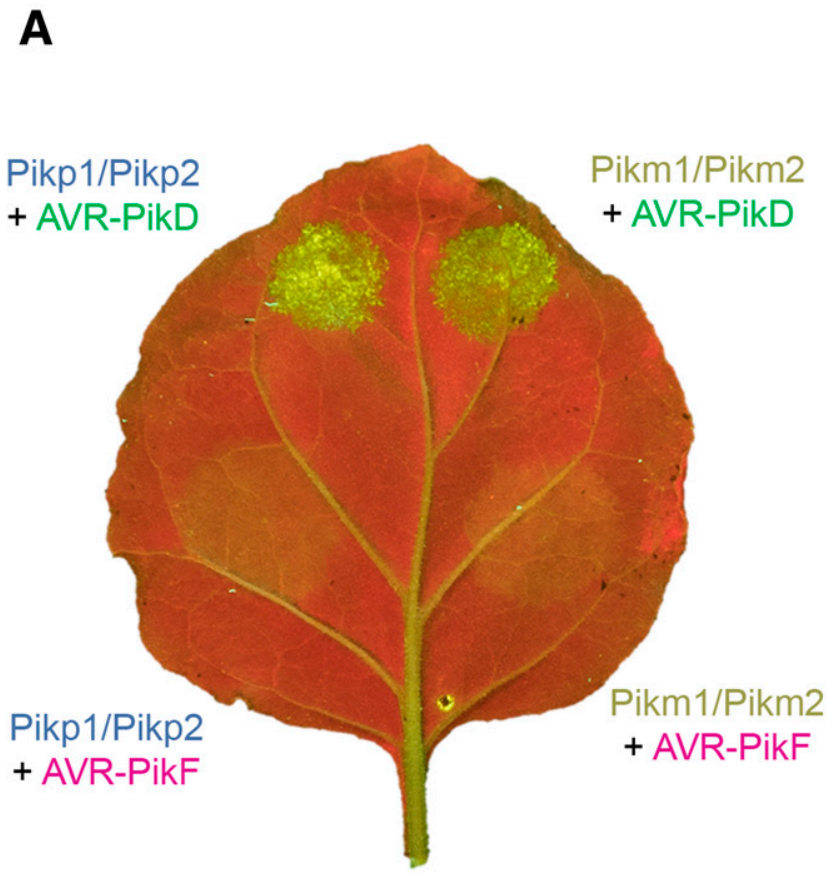

rice breeding programs in Thailand is not sustainable in the long term, as the blast fungus can overcome this resistance by deletion or mutation of $A V R-P i k D$. The identification of new natural $P i k$ resistance alleles with a broader recognition range for $A V R-P i k$ or engineering new Pik alleles that can detect a wider range of $A V R-P i k$ variants (including $A V R-P i k F$ ), or both, is required.
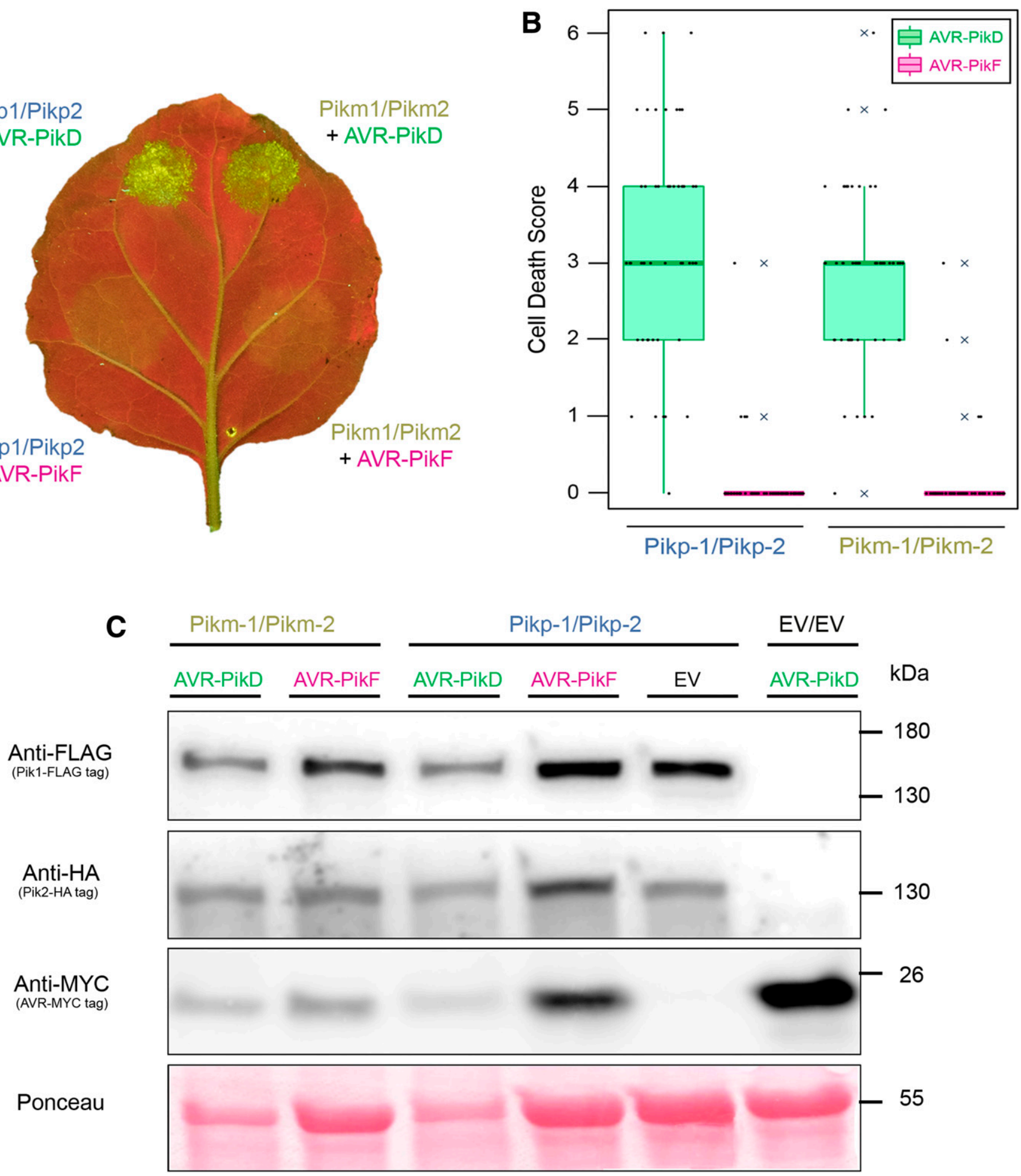

Fig. 7. Neither Pikp-1/Pikp-2 nor Pikm-1/Pikm-2 trigger cell death in the presence of AVR-PikF in Nicotiana benthamiana. A, Representative leaf image showing cell-death response of Pikp-1/Pikp-2 and Pikm-1/Pikm-2 to either AVR-PikD or AVR-PikF, as autofluorescence characteristic of hypersensitive response-like cell death under UV light. Images were taken 5 days postinfiltration. B, Box plot summarizing the results obtained from 55 leaves in three independent experiments. Leaves were scored according to the scale by Maqbool et al. (2015). C, Western blots confirming expression of the proteins in a blot was probed with appropriate antibody for the tagged protein. Ponceau stain was used for control. 


\section{MATERIALS AND METHODS}

Plant materials.

Rice variety JHN, a nonglutinous rice variety with long and deep purple grain, was used. JHN demonstrated broad-spectrum resistance against the rice blast pathogens in Thailand. Rice cultivar KDML105, aromatic and high-quality long grain rice, was used as susceptible rice cultivar. IRBL NILs of the rice blast-resistant gene Pik, including Pik, Pikm, Pikp, Piks, Pikh, Pil, and Pi7, provided by IRRI, were used. Rice cultivar LTH was used as NIL background and susceptible control.

\section{Rice blast materials.}

A total of 60 rice blast isolates were used, including 58 isolates collected from Thailand rice-growing areas, representing the central, northern, and northeastern parts of Thailand. Two rice blast isolates, 70-15 and Guy11, were used as reference isolates (Table 1; Supplementary Fig S1).

\section{Fungal culture and genomic DNA extraction.}

The stock of each blast isolate in filter paper was cultured on RFA medium plates for 7 to 10 days. After mycelium growth, the mycelia were grown in potato dextrose broth medium and the cultures were incubated at $28^{\circ} \mathrm{C}$ for 7 days, with an orbital shaker (180 rpm). The mycelia were isolated from the medium on Whatman no. 1 filtration paper and, then, were frozen in liquid nitrogen and ground to a fine powder. Mycelial powder was extracted by the cetyltrimethylammonium bromide method $(10 \mathrm{mM}$ Tris- $\mathrm{HCl}, \mathrm{pH}$ 8.0, 1 mM EDTA, $100 \mathrm{mM} \mathrm{NaCl}, 2 \%$ sodium dodecyl sulfate [SDS]). DNA quality analyzed by gel electrophoresis and DNA quantitative analyzed by NanoDrop 2000 spectrophotometer (Thermo Fisher Scientific Inc.).

\section{Genetic variation in M. oryzae AVR-Pik.}

The following $A V R$-Pik gene-specific primers were designed: AVR-Pik F: 5' - GCGCCCATGCATTATCTTAT-3' and AVR-Pik R: 5'-TGAAGGTCACGGTTTGAAGA-3'. The volume of the PCR reaction mixture was $20 \mu \mathrm{l}$, containing $1 \mu \mathrm{l}$ of $50-\mathrm{ng} / \mu \mathrm{l}$ template DNA, $0.25 \mu \mathrm{M}$ of each primer, $1.25 \mathrm{mM} \mathrm{MgCl}_{2}, 0.1 \mathrm{mM}$ dNTPs, $1 \times$ buffer A, and $0.2 \mu$ l of Taq DNA polymerase enzyme (Vivantis). PCR was performed under the following conditions: initial activation at $94^{\circ} \mathrm{C}$ for $5 \mathrm{~min}, 35$ cycles of denaturation at $94^{\circ} \mathrm{C}$ for $30 \mathrm{~s}$, annealing at $54^{\circ} \mathrm{C}$ for $30 \mathrm{~s}$, and extension at $72^{\circ} \mathrm{C}$ for $30 \mathrm{~s}$, followed by a final incubation at $72^{\circ} \mathrm{C}$ for $5 \mathrm{~min}$, using a Mastercycler Nexus (Eppendorf). PCR products were visualized by separated in $1.5 \%$ agarose gel, DNA staining with ethidium bromide and used Gel Doc XR+ with Image Lab software (Bio-Rad). The PCR products were purified and the buffer was replaced with elution buffer, using an Ambiclean kit (Vivantis). Purified PCR products were submitted for sequencing service (Macrogen) and were translated to amino acid sequences. Alleles of $A V R-P i k$ were identified by a total of five DNA substitutions.

\section{Copy number analysis.}

Quantitative real-time PCR. Rice blast isolates with different copy numbers of the AVR-Pik gene were used for the analysis. The PCR amplification with AVR-Pik primers and detection was carried out in a MasterCycler Realplex4 thermal cycler (Eppendorf). The relative copy number of the candidate gene was calculated using the comparative $\mathrm{Ct}\left(2^{\Delta \mathrm{Ct}}\right)$ method by normalization to the IDM DNA-directed RNA polymerase I subunit RPA1 fragment gene: IDM F, 5'-GACCTATGCAAT CACCAC-3' and IDM R, 5'-CGTACTCGAGTGTAATCTCG$3^{\prime}$. The PCR reactions (total volume $20 \mu \mathrm{l}$ ) were performed using $1 \mu \mathrm{l}$ of each $50-\mathrm{ng} / \mu \mathrm{l}$ genomic DNA, $1 \times$ of QPCR Green Master Mix LRox (Biotech rabbit), and $0.2 \mu \mathrm{M}$ of each primer.
PCR amplification was performed at $95^{\circ} \mathrm{C}$ for $2 \mathrm{~min}, 30$ cycles of denaturation at $95^{\circ} \mathrm{C}$ for $10 \mathrm{~s}$, annealing at $58^{\circ} \mathrm{C}$ for $10 \mathrm{~s}$, and extension at $72^{\circ} \mathrm{C}$ for $20 \mathrm{~s}$, with three biological replications.

Southern blotting. Twenty micrograms of rice blast genomic DNA from isolates with different $A V R$-Pik alleles were digested with restriction enzymes BamHI or PstI (BioLabs Inc.), were fractionated through a $0.8 \%$ agarose gel in $0.5 \times$ Tris-borateEDTA buffer, with $75-\mathrm{V}$ electrophoresis for $3 \mathrm{~h}$, and were processed in denaturation buffers (1.5 M NaCl, 0.5 M NaOH) for $30 \mathrm{~min}$. The gel was then incubated in the neutralization buffer (1.5 M NaCl, 0.5 M TrisHCl, $\mathrm{pH} 7.4$ ) for $15 \mathrm{~min}$ before transferring DNA to a nitrocellulose membrane. The DNA was cross-linked to the membrane by UV cross-linking. AVR-Pik fragment was used as probe, biotin-labeled probes were generated by PCR with biotin-16-dUTP (Roche Diagnostics Corp.). The membrane was hybridized overnight with biotinlabeled probes in DIG Easy Hyb solution (Roche Diagnostics Corp.) at $45^{\circ} \mathrm{C}$. The hybridized membrane was washed four times by $2 \times \mathrm{SSC}(1 \times \mathrm{SSC}$ is $0.15 \mathrm{M} \mathrm{NaCl}$ plus $0.015 \mathrm{M}$ sodium citrate), $1 \times \mathrm{SSC}, 0.5 \times \mathrm{SSC}$, and $0.1 \times \mathrm{SSC}$ with $0.1 \%$ SDS. Posthybridization was also performed according to the manufacturer protocol of DIG-High Prime DNA labeling and detection starter kit I (Roche Diagnostics Corp.). After hybridization, the membrane was washed and was blocked in solution containing solutions I (maleic acid buffer with $0.3 \%$ of Tween 20), II (9:1, maleic acid buffer, blocking solution [Roche Diagnostics Corp.]), antibody solution (9:1:1, maleic acid buffer, blocking solution, Anti-Dig [Roche Diagnostics Corp.]), and detection buffer, $\mathrm{pH} 9.5(10 \mathrm{ml}$ of $5 \mathrm{M} \mathrm{NaCl}, 6 \mathrm{~g}$ of Tris, $25 \mathrm{ml}$ of $1 \mathrm{M} \mathrm{MgCl}_{2}$ ), under shaker condition at room temperature for $15,30,30$, and $5 \mathrm{~min}$, respectively. The antibody solution contains anti-DIG, the chemiluminescent reaction was carried out with CDP-Star (Roche Diagnostics Corp.) chemiluminescent substrate. The membrane was exposed to X-ray film for $15 \mathrm{~min}$ and the film was developed and fixed in a darkroom.

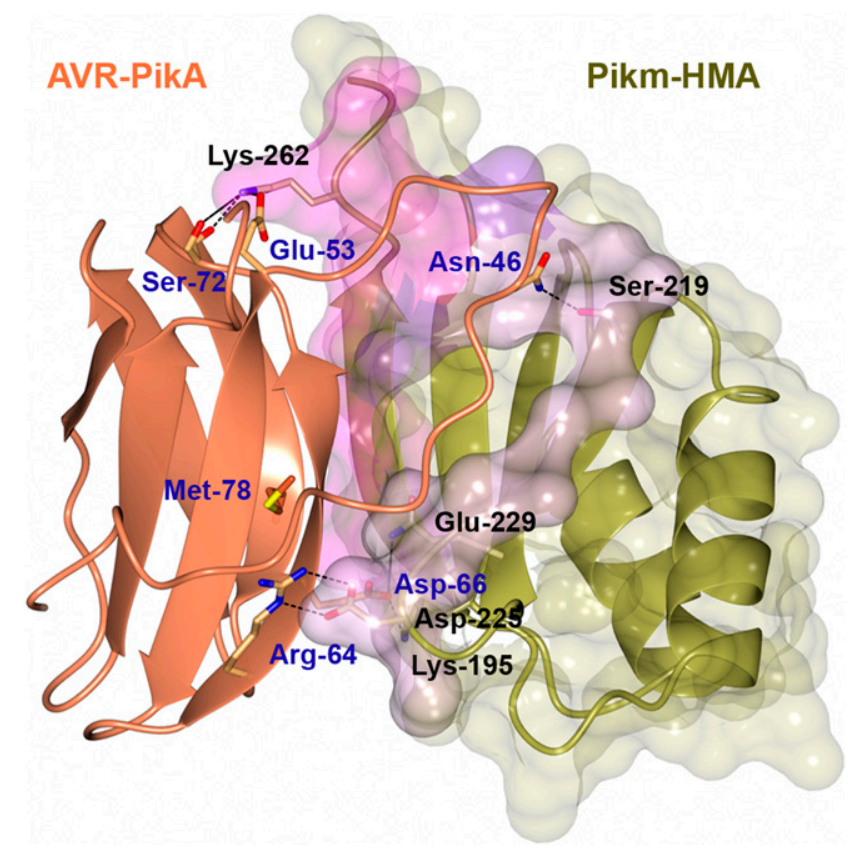

Fig. 8. Schematic representation of the AVR-PikA/Pikm-HMA complex. The structure of Pikm-HMA is shown in the right helix ribbon and AVRPikA in the left ribbon. Each protein interface in the complex was described by De la Concepcion et al. 2018. In AVR-PikF this amino acid is a lysine and due to its location, this residue likely disrupts complex formation between AVR-Pik and Pik-HMAs. 
Pathogenicity assay. Rice seedlings (21 days old) were spray-inoculated with fungal spores of isolates with different AVR-Pik alleles (AVR-PikA, AVR-PikC, AVR-PikD, AVR-PikE, $A V R-P i k F$, and two-copy isolates), approximately $10^{5}$ spores per milliliter (about $20 \mathrm{ml}$ of inoculum per experiment) adding $5 \mathrm{ml}$ of $2.5 \%$ gelatin and shaking well. After inoculation, the plants were placed inside a dark room $\left(100 \%\right.$ humidity at $25^{\circ} \mathrm{C}$ for $24 \mathrm{~h}$ ) and were then transferred to a greenhouse high humidity room. Disease evaluation was assessed at 7 days postinoculation. The assays were repeated three times with similar results.

AVR-Pik expression. Susceptible rice cultivar KDML105 (21 days old) was spray-inoculated with three rice blast isolates, the isolate with $A V R-P i k D$, the isolate with $A V R-P i k F$, and the isolate with two copies of $A V R$-Pik gene. RNA was extracted, using the total RNA extraction kit (Vivatis), $72 \mathrm{~h}$ after inoculation by cutting an inoculated rice leaf, immediately freezing it in liquid nitrogen and grinding it to a fine powder. RNA was converted to cDNA using $200 \mathrm{U}$ MMuLV reverse transcription (Biotech rabbit), $2 \mathrm{mM}$ dNTP, $0.25 \mu \mathrm{M}$ Oligo $(\mathrm{dT})_{18}, 1 \times \mathrm{MMuLV}$ reverse transcriptase buffer, $5 \mu \mathrm{g}$ of RNA template, total volume of $20 \mu \mathrm{l}$. Mixtures were incubated at $42^{\circ} \mathrm{C}$ for $45 \mathrm{~min}$, before inactivating the enzyme at $85^{\circ} \mathrm{C}$ for $10 \mathrm{~min}$. The cDNA from each sample was diluted 10 times and was used as the template for $A V R-P i k$ expression analysis. $A V R$ $P i k \_c d s$ primers were designed from $A V R$-Pik start to stop region: AVR-Pik_cds F, 5'-ATGCGTGTTACCACTTTTAAC AC-3' and $A V R-P i k \_c d s$ R, 5' -TTAAAAGCCGGGCCTTTTT T-3'. The PCR reaction was performed in a $20-\mu$ reaction mixture containing $1 \mu \mathrm{l}$ of diluted cDNA, $0.25 \mu \mathrm{M}$ of each primer, $1.25 \mathrm{mM} \mathrm{MgCl} 2,0.1 \mathrm{mM}$ dNTPs, $1 \times$ buffer $\mathrm{A}$, and $0.2 \mu \mathrm{l}$ of Taq DNA polymerase enzyme (Vivantis). PCR was performed with the following conditions: initial activation at $94^{\circ} \mathrm{C}$ for $5 \mathrm{~min}, 35$ cycles of denaturation at $94^{\circ} \mathrm{C}$ for $30 \mathrm{~s}$, annealing at $54^{\circ} \mathrm{C}$ for $30 \mathrm{~s}$, and extension at $72^{\circ} \mathrm{C}$ for $30 \mathrm{~s}$, followed by a final incubation at $72^{\circ} \mathrm{C}$ for $5 \mathrm{~min}$, using a Mastercycler Nexus (Eppendorf). The PCR products were purified and the buffer was replaced with elution buffer, using an Ambiclean kit (Vivantis). Purified PCR products were submitted for sequencing (Macrogen) and were translated to amino acid sequences to determine the AVR-Pik alleles expressed.

Gel filtration. Pikm-HMA, Pikp-HMA with cleavable Cterminal $6 \times$ His tag, and AVR-Pik effectors with a cleavable $\mathrm{N}$ terminal maltose-binding protein tag and a noncleavable $\mathrm{C}$-terminal $6 \times$ His tag were produced in E. coli SHuffle cells (Biolabs, England) and were purified as previously described (De la Concepcion et al. 2018; Maqbool et al. 2015). Analytical size exclusion chromatography was performed at $4^{\circ} \mathrm{C}$, using a Superdex 75 10/300 gel filtration column (GE Healthcare) pre-equilibrated in $50 \mathrm{mM}$ HEPES, $\mathrm{pH} 7.5$, and $150 \mathrm{mM} \mathrm{NaCl}$. Pik-HMAs and AVR-Pik effectors were mixed in a molar ratio of $2: 1$ and were incubated on ice for $60 \mathrm{~min}$. Individual and mixed proteins $(120 \mu \mathrm{l})$ were injected at a flow rate of $0.5 \mathrm{ml} / \mathrm{min}$ and $0.5-\mathrm{ml}$ fractions were collected for analysis by SDS-polyacrylamide gel electrophoresis. Each experiment was repeated a minimum of three times, with similar results.

N. benthamiana cell-death assays. Agrobacterium tumefaciens GV3101 was transformed with the relevant binary constructs. Four-week-old $N$. benthamiana plants were infiltrated with transformed A. tumefaciens using a needleless syringe. Two leaves were infiltrated from each plant. The infiltration position of each NLR-effector combination was varied between replicate leaves to account for within-leaf variation in transient expression (Bashandy et al. 2015). The final optical density at $600 \mathrm{~nm}$ of A. tumefaciens cultures for infiltration was 1.5 (Pik$1=0.4$, Pik-2 $=0.4$, effector $=0.6$, p19 $=0.1$ ). Infiltrated plants were grown in a controlled environment room $\left(22^{\circ} \mathrm{C}\right.$ constant temperature, $80 \%$ relative humidity, 16 -h photoperiod). Infiltrated leaves were photographed in white (adaxial surface) and UV light (abaxial surface) 5 days postinfiltration. The presence and extent of cell death was scored on a scale of 0 to 6 as used by Maqbool et al. (2015). Box plots represent data from three independent experiments and were produced using $\mathrm{R}$ v3.4.0 and the ggplot2 package (Wickham 2016). The box extends from Q1 to Q3, with the central line representing the median. Outliers (> Q3 + 1.5 $\times$ IQR or $<$ Q1 $-1.5 \times \mathrm{IQR})$ are indicated by crosses. Box whiskers extend to the highest or lowest nonoutlier value. The presence of each protein, as expressed in representative assays, was determined by Western blot with the appropriate antibody, anti-Flag, anti-hemagglutinin (HA), anti-Myc for Pik-1-Flag, Pik-2-HA, and AVR-Pik-Myc, respectively.

M. oryzae genome sequence. Genomic DNA of rice blast isolate 10100 was used as a representative of isolate with two copies of AVR-Pik gene. Sequencing libraries were constructed using a NEB kit for Illumine Hiseq PE 150, following manufacturer recommendations (NovoGene Bioinformatics Technology Co., Ltd.). Raw reads were first cleaned by removing adaptor sequences and low quality sequences, Q-value $\leq 53$ exceed the certain threshold $40 \%$ of the read length by default, eliminated reads with unknown nucleotides larger than $10 \%$ and reads that overlap with adapter over certain threshold ( 15 bp by default). Sanger base quality $<200$ bp were cut off. The clean reads were mapped to the Magnaporthe oryzae 70-15 reference genome (GenBank accession GCA_000002495.2) using BWA alignment. Finally, $1.6 \mathrm{~Gb}(46 \times$ coverage) sequence reads were retained for genome assembly using two programs, velveth and velvetg, from Velvet de novo assembler (Zerbino and Birney 2008).

\section{LITERATURE CITED}

Ashikawa, I., Hayashi, N., Yamane, H., Kanamori, H., Wu, J., Matsumoto, T., Ono, K., and Yano, M. 2008. Two adjacent nucleotide-binding siteleucine-rich repeat class genes are required to confer Pikm-specific rice blast resistance. Genetics 180:2267-2276.

Bashandy, H., Jalkanen, S., and Teeri, T. H. 2015. Within leaf variation is the largest source of variation in agroinfiltration of Nicotiana benthamiana. Plant Methods 11:47.

Chaipanya, C., Telebanco-Yanoria, M. J., Quime, B., Longya, A., Korinsak, S., Korinsak, S., Toojinda, T., Vanavichit, A., Jantasuriyarat, C., and Zhou, B. 2017. Dissection of broad-spectrum resistance of the Thai rice variety Jao Hom Nin conferred by two resistance genes against rice blast. Rice (N. Y.) 10:18.

Chuma, I., Isobe, C., Hotta, Y., Ibaragi, K., Futamata, N., Kusaba, M., Yoshida, K., Terauchi, R., Fujita, Y., Nakayashiki, H., Valent, B., and Tosa, Y. 2011. Multiple translocation of the AVR-Pita effector gene among chromosomes of the rice blast fungus Magnaporthe oryzae and related species. PLoS Pathog. 7:e1002147.

Costanzo, S., and Jia, Y. 2010. Sequence variation at the rice blast resistance gene Pikm locus: Implications for the development of allele specific markers. Plant Sci. 178:523-530.

Couch, B. C., and Kohn, L. M. 2002. A multilocus gene genealogy concordant with host preference indicates segregation of a new species, Magnaporthe oryzae, from M. grisea. Mycologia 94:683-693.

Dai, Y., Jia, Y., Correll, J., Wang, X., and Wang, Y. 2010. Diversification and evolution of the avirulence gene AVR-Pital in field isolates of Magnaporthe oryzae. Fungal Genet. Biol. 47:973-980.

De la Concepcion, J. C., Franceschetti, M., Maqbool, A., Saitoh, H., Terauchi, R., Kamoun, S., and Banfield, M. J. 2018. Polymorphic residues in rice NLRs expand binding and response to effectors of the blast pathogen. Nat. Plants 4:576-585.

Disthaporn, S. 1994. Current rice blast epidemics and their management in Thailand. Pages 333-342 in: Rice Blast Disease. R. S. Zeigler, S. A. Leong, and P. S. Teng, eds. CAB International, Wallingford, U.K. in association with IRRI, Manila, Philippines.

Dodds, P. N., and Rathjen, J. P. 2010. Plant immunity: Towards an integrated view of plant-pathogen interactions. Nat. Rev. Genet. 11: 539-548. 
Fudal, I., Böhnert, H. U., Tharreau, D., and Lebrun, M. H. 2005. Transposition of MINE, a composite retrotransposon, in the avirulence gene ACE1 of the rice blast fungus Magnaporthe grisea. Fungal Genet. Biol. 42:761-772.

Fudal, I., Ross, S., Brun, H., Besnard, A. L., Ermel, M., Kuhn, M. L. Balesdent, M. H., and Rouxel, T. 2009. Repeat-induced point mutation (RIP) as an alternative mechanism of evolution toward virulence in Leptosphaeria maculans. Mol. Plant-Microbe Interact 22:932-941.

Hogenhout, S. A., Van der Hoorn, R. A. L., Terauchi, R., and Kamoun, S. 2009. Emerging concepts in effector biology of plant-associated organisms. Mol. Plant-Microbe Interact 22:115-122.

Jia, Y., McAdams, S. A., Bryan, G. T., Hershey, H. P., and Valent, B. 2000. Direct interaction of resistance gene and avirulence gene products confers rice blast resistance. EMBO J. 19:4004-4014.

Kaewcheenchai, R., Sriwisut, S., Noenplab, A., Nalampangnoenplab, A., Ruksopa, K., Dungsoongnern, P., Promnart, U., and Rasidee, N. 2014. Improving blast resistance in a rice variety 'Bahng Taen' by using markerassisted backcrossing. Proceeding of the $32^{\text {nd }}$ Rice and Temperate Cereal Crop Annual Conference, Petchaburi, Thailand. 158-170.

Kang, S., Sweigard, J. A., and Valent, B. 1995. The $P W L$ host specificity gene family in the blast fungus Magnaporthe grisea. Mol. Plant-Microbe Interact 8:939-948.

Kanzaki, H., Yoshida, K., Saitoh, H., Fujisaki, K., Hirabuchi, A., Alaux, L., Fournier, E., Tharreau, D., and Terauchi, R. 2012. Arms race coevolution of Magnaporthe oryzae AVR-Pik and rice Pik genes driven by their physical interactions. Plant J. 72:894-907.

Khanthong, S., Jantasuriyarat, C., and Katengam, S. 2010. Blast disease and rice breeding for blast disease resistance through marker-assisted selection. Thai J. Genet. 3:106-119.

Kiyosawa, S. 1982. Genetics and epidemiological modelling of breakdown of plant disease resistance. Annu. Rev. Phytopathol. 20:93-117.

Kotchasatit, A. 2013. An early maturing, non-glutinous promising rice line resistant to blast. Proceedings of the $30^{\text {th }}$ Rice and Temperate Cereal Crops Annual Conference 2013, Bangkok, Thailand. 56-71.

Kusaba, M., Mochida, T., Naridomi, T., Fujita, Y., Chuma, I., and Tosa, Y. 2014. Loss of a $1.6 \mathrm{Mb}$ chromosome in Pyricularia oryzae harboring two alleles of AvrPik leads to acquisition of virulence to rice cultivars containing resistance alleles at the Pik locus. Curr. Genet. 60:315-325.

Langner, T., Białas, A., and Kamoun, S. 2018. The blast fungus decoded: Genomes in flux. MBio 9:e00571-18.

Li, W., Wang, B., Wu, J., Lu, G., Hu, Y., Zhang, X., Zhang, Z., Zhao, Q., Feng, Q., Zhang, H., Wang, Z., Wang, G., Han, B., Wang, Z., and Zhou, B. 2009. The Magnaporthe oryzae avirulence gene AvrPiz-t encodes a predicted secreted protein that triggers the immunity in rice mediated by the blast resistance gene Piz-t. Mol. Plant-Microbe Interact 22:411-420.

Liu, W., Liu, J., Triplett, L., Leach, J. E., and Wang, G. L. 2014. Novel insights into rice innate immunity against bacterial and fungal pathogens. Annu. Rev. Phytopathol. 52:213-241.

Luo, C. X., Yin, L. F., Ohtaka, K., and Kusaba, M. 2007. The 1.6Mb chromosome carrying the avirulence gene AvrPik in Magnaporthe oryzae isolate $84 \mathrm{R}-62 \mathrm{~B}$ is a chimera containing chromosome 1 sequences. Mycol. Res. 111:232-239.

Maqbool, A., Saitoh, H., Franceschetti, M., Stevenson, C. E. M., Uemura, A., Kanzaki, H., Kamoun, S., Terauchi, R., and Banfield, M. J. 2015. Structural basis of pathogen recognition by an integrated HMA domain in a plant NLR immune receptor. eLife 4:e08709.

Nalampangnoenplab, A. 2011. Minimization of rice blast severity by means of multilines in the lower north. Pages 225-241 in: Proceedings of Rice Research Symposium 2011. Rice Research Center Groups in Upper and Lower Northern Region, Phrae, Thailand.

Noenplab, A., Nalumpangnernplub, A., and Palawisut, S. 2015. Increasing blast resistance in HPSL1 using marker assisted selection. Pages 3-16 in: Proceeding of the 8th Rice Research Conference 2015. Chiang Rai, Thailand. Rice Research Center Groups in Upper and Lower Northern Region, Phrae, Thailand.

Noenplab, A., Vanavichit, A., Toojinda, T., Sirithunya, P., Tragoonrung, S., Sriprakhon, S., and Vongsaprom, C. 2006. QTL mapping for leaf and neck blast resistance in Khao Dawk Mali 105 and Jao Horm Nin recombinant inbred lines. Sci. Asia 32:133-142.

Orbach, M. J., Farrall, L., Sweigard, J. A., Chumley, F. G., and Valent, B. 2000. A telomeric avirulence gene determines efficacy for the rice blast resistance gene Pi-ta. Plant Cell 12:2019-2032.

Rafiqi, M., Ellis, J. G., Ludowici, V. A., Hardham, A. R., and Dodds, P. N. 2012. Challenges and progress towards understanding the role of effectors in plant-fungal interactions. Curr. Opin. Plant Biol. 15:477-482.
Ray, S., Singh, P. K., Gupta, D. K., Mahato, A. K., Sarkar, C., Rathour, R., Singh, N. K., and Sharma, T. R. 2016. Analysis of Magnaporthe oryzae genome reveals a fungal effector, which is able to induce resistance response in transgenic rice line containing resistance gene, Pi54. Front. Plant Sci. 7:1140.

Ribot, C., Césari, S., Abidi, I., Chalvon, V., Bournaud, C., Vallet, J., Lebrun, M. H., Morel, J. B., and Kroj, T. 2013. The Magnaporthe oryzae effector AVR1-CO39 is translocated into rice cells independently of a fungalderived machinery. Plant J. 74:1-12.

Saleh, D., Milazzo, J., Adreit, H., Fournier, E., and Tharreau, D. 2014. South-east Asia is the center of origin, diversity and dispersion of the rice blast fungus, Magnaporthe oryzae. New Phytol. 201:1440-1456.

Sirisathaworn, T., Srirat, T., Longya, A., and Jantasuriyarat, C. 2017. Evaluation of mating type distribution and genetic diversity of three Magnaporthe oryzae avirulence genes, PWL-2, AVR-Pii and Avr-Piz-t, in Thailand rice blast isolates. ANRES 51:7-14.

Sreewongchai, T., Toojinda, T., Thanintorn, N., Kosawang, C., Vanavichit, A., Tharreau, D., and Sirithunya, P. 2010. Development of elite indica rice lines with wide spectrum of resistance to Thai blast isolates by pyramiding multiple resistance QTLs. Plant Breed. 129:176-180.

Sweigard, J. A., Carroll, A. M., Kang, S., Farrall, L., Chumley, F. G., and Valent, B. 1995. Identification, cloning, and characterization of PWL2, a gene for host species specificity in the rice blast fungus. Plant Cell 7:1221-1233.

Takahashi, M., Ashizawa, T., Hirayae, K., Moriwaki, J., Sone, T., Sonoda, R., Noguchi, M. T., Nagashima, S., Ishikawa, K., and Arai, M. 2010. One of two major paralogs of AVR-Pital is functional in Japanese rice blast isolates. Phytopathology 100:612-618.

Tsujimoto Noguchi, M. 2011. Parasexual recombination in Magnaporthe oryzae. Jpn. Agric. Res. Q. 45:39-45.

Waiyawuththanapoom, P., Waiyawuththanapoom, W., and Tirastittam, P. 2015. Social media as a distribution channel for Thailand's rice berry product. World Acad. Sci. Eng. Technol. 9:194-197.

Wang, B., Ebbole, D. J., and Wang, Z. 2017. The arms race between Magnaporthe oryzae and rice: Diversity and interaction of $A v r$ and $R$ genes. J. Integr. Agric. 16:2746-2760.

Wickham, H. 2016. ggplot2: Elegant graphics for data analysis. SpringerVerlag, New York.

Wongsaprom, C., Sirithunya, P., Vanavichit, A., Pantuwan, G., Jongdee, B., Sidhiwong, N., Lanceras-Siangliw, J., and Toojinda, T. 2010. Two introgressed quantitative trait loci confer a broad-spectrum resistance to blast disease in the genetic background of the cultivar RD6 a Thai glutinous jasmine rice. Field Crops Res. 119:245-251.

Wu, J., Kou, Y., Bao, J., Li, Y., Tang, M., Zhu, X., Ponaya, A., Xiao, G., Li, J., Li, C., Song, M. Y., Cumagun, C. J. R., Deng, Q., Lu, G., Jeon, J. S., Naqvi, N. I., and Zhou, B. 2015. Comparative genomics identifies the Magnaporthe oryzae avirulence effector AvrPi9 that triggers Pi9mediated blast resistance in rice. New Phytol. 206:1463-1475.

Yajai, P., and Ketsuwan, K. 2015. The use of anther culture for developing rice blast resistant true breeding lines. Pages 47-52 in: Proceedings of the 8th Rice Research Conference 2015. Rice Research Center Groups in Upper and Lower Northern Region, Chiang Rai, Thailand.

Yamasaki, Y., and Niizeki, H. 1965. Studies on variation of the rice blast fungus, Pyricularia oryzae Cav. I. Karyological and genetic studies on variation. Bull. Natl. Inst. Agric. Sci. Jpn. 13:231-273.

Yoshida, K., Saitoh, H., Fujisawa, S., Kanzaki, H., Matsumura, H., Yoshida, K., Tosa, Y., Chuma, I., Takano, Y., Win, J., Kamoun, S., and Terauchi, R. 2009. Association genetics reveals three novel avirulence genes from the rice blast fungal pathogen Magnaporthe oryzae. Plant Cell 21: 1573-1591.

Zeigler, R. S., Scott, R. P., Leung, H., Bordeos, A. A., Kumar, J., and Nelson, R. J. 1997. Evidence of parasexual exchange of DNA in the rice blast fungus challenges its exclusive clonality. Phytopathology 87: 284-294.

Zerbino, D. R., and Birney, E. 2008. Velvet: Algorithms for de novo short read assembly using de Bruijn graphs. Genome Res. 18:821-829.

Zhang, H., Wu, Z., Wang, C., Li, Y., and Xu, J. R. 2014. Germination and infectivity of microconidia in the rice blast fungus Magnaporthe oryzae. Nat. Commun. 5:4518.

Zhang, S., Wang, L., Wu, W., He, L., Yang, X., and Pan, Q. 2015. Function and evolution of Magnaporthe oryzae avirulence gene AvrPib responding to the rice blast resistance gene Pib. Sci. Rep. 5:11642.

Zhou, E., Jia, Y., Singh, P., Correll, J. C., and Lee, F. N. 2007. Instability of the Magnaporthe oryzae avirulence gene AVR-Pita alters virulence. Fungal Genet. Biol. 44:1024-1034. 